\title{
LA NUEVA UNIÓN EUROPEA: DE LA DOBLE PERSONALIDAD A LA CRISIS DE PERSONALIDAD
}

JOSÉ RAMÓN CANEDO ARRILLAGA LUIS IGNACIO GORDILLO PÉREZ 
SUMARIO

1. CONSIDERACIONES PRELIMINARES. 2. EL CONCEPTO DE PERSONALIDAD JURÍDICA EN LAS ORGANIZACIONES INTERNACIONALES. 3. LA CONTROVERTIDA PERSONALIDAD JURÍDICA INTERNACIONAL DE LA UNIÓN EUROPEA. 3.1. La discutida personalidad internacional de la Unión Europea. 3.2. Práctica convencional y diplomática. 4. LA UNIÓN EUROPEA COMO UNA ÚNICA ORGANIZACIÓN. 


\section{LA NUEVA UNIÓN EUROPEA: DE LA DOBLE PERSONALIDAD A LA CRISIS DE PERSONALIDAD}

POR

JOSÉ RAMÓN CANEDO ARRILLAGA

Profesor de Derecho de la Unión Europea (Universidad de Deusto)

\section{LUIS IGNACIO GORDILLO PÉREZ}

Profesor de Derecho constitucional (Universidad de Deusto)

\section{CONSIDERACIONES PRELIMINARES ${ }^{1}$}

1. Como es bien sabido, el conocido como Tratado de Lisboa, Tratado de reforma general del sistema de la Unión Europea, ha entrado en vigor el pasado 1 de diciembre de 2009, en virtud de lo dispuesto en su artículo 6, párrafo 2 in fine. Dicha reforma habría procedido supuestamente a una simplificación radical del sistema, por un lado, haciendo desaparecer la por algunos denostada estructura de tres pilares, y, por otro, sustituyendo todas las organizaciones existentes por una única que sería la Unión Europea. Ni una cosa ni la otra son ciertas: si bien lo es que la Unión Europea ya no se fundamenta en las Comunidades Europeas complementadas con las políticas y las cooperaciones establecidas por el Tratado (configurando estas últimas los pilares dos y tres), no lo es menos que la Política Exterior y de Seguridad Común sigue gozando de un sta-

1 A los efectos de evitar confusiones, las disposiciones del Tratado de la Unión Europea anteriores a la reforma operada por el Tratado de Lisboa se citarán usando la abreviatura TUE y las posteriores, con la abreviatura TUE-L. 
tus especial dentro de la Unión ${ }^{2}$; en segundo lugar, y pese a ser cierto que la Comunidad Europea ha desaparecido como organización internacional, no debemos olvidar que la Comunidad Europea de la Energía Atómica subsiste 3 .

A pesar de todo lo anterior, lo cierto es que el nuevo Tratado confiere expresamente a la Unión Europea personalidad jurídica (artículo 47 TUE-L).

2. Los Estados miembros establecieron, como objetivo expreso para la Unión Europea, «afirmar su identidad en el ámbito internacional» (artículo 2, párrafo 2o TUE). Para garantizar la eficacia de la Unión Europea como «fuerza de cohesión» en las relaciones internacionales (artículo 11.2 TUE), el Tratado de la Unión Europea diseñó un marco para una Política Exterior y de Seguridad Común (PESC) en el título V. Sin embargo, las Comunidades Europeas han estado participando en transacciones internacionales en el ámbito de sus respectivas competencias desde el momento de su creación. La Unión Europea se vio atribuida la tarea de asegurar la consistencia de sus actividades exteriores en su conjunto en las áreas afectadas por las políticas de la Comunidad y las propias de la Política Exterior y de Seguridad Común. En efecto, según el artículo 3, párrafo $2^{\circ}$ del TUE:

«La Unión velará, en particular, por mantener la coherencia del conjunto de su acción exterior en el marco de sus políticas en materia de relaciones exteriores, de seguridad, de economía y de desarrollo. El Consejo y la Comisión tendrán la responsabilidad de garantizar dicha coherencia y cooperarán a tal fin. Asegurarán, cada cual conforme a sus competencias, la realización de tales políticas».

3. A pesar de estas importantes tareas, y a diferencia de la Comunidad, los tratados no asignaron expresamente personalidad internacional a la Unión Europea con lo que algunos autores han negado, incluso, su existencia como realidad jurídica. En las líneas siguientes se analizará la cuestión de si la Unión ha dispuesto o no de personalidad jurídica como tal, qué consecuencias han podido derivarse de ello y, finalmente, cuál ha sido la práctica diplomática y convencional en la materia.

${ }^{2}$ A tal punto que hay autores, como DASHWOOD, que afirman que sigue existiendo una estructura de dos pilares. Vide House of Lords, European Union Committee (2009), The Treaty of Lisbon: an impact assessment, Vol. I, (http://www.publications.parliament.uk/pa/ld200708/ ldselect/ldeucom/62/62.pdf) (última consulta: 14-diciembre-2009).

3 De hecho, el Tratado de Lisboa ha procedido a reformar el citado tratado sectorial. Tales reformas se recogen en el Protocolo n. ${ }^{\circ} 2$ anejo al propio Tratado de Lisboa. Por otro lado, Alemania, Irlanda, Hungría, Austria y Suecia han propuesto, a través de la Declaración n. ${ }^{\circ}$ 54, llevar a cabo una reforma en profundidad de la Comunidad Europea de la Energía Atómica en el futuro próximo. 
4. Al término "Unión Europea» se le han dado muchos y muy diferentes significados a lo largo de los años. Así, se ha venido usando desde 1972 para referirse genéricamente a una «etapa cualitativamente avanzada de la integración europea» ${ }^{4}$. Sin embargo, el concepto de "Unión Europea», tal y como fue oficialmente establecido por el Tratado de Maastricht, pretendía servir a un fin bien diferente, esto es, servir de "paraguas» bajo el que se cobijasen los dos nuevos regímenes de cooperación intergubernamental junto con las Comunidades ya existentes. Así pues, la estructura de pilares está inseparablemente unida a la invención jurídica del término «Unión Europea» y ha de servir de base en la reflexión sobre la naturaleza legal de la UE.

La considerable perplejidad de la doctrina comunitaria en relación con la UE se puede ilustrar fácilmente apelando a los numerosos libros y artículos publicados ya vigente Maastricht que continuaban hablando exclusivamente de la Comunidad Europea y preferían ignorar las otras dimensiones del Derecho de la UE e incluso su existencia misma ${ }^{5}$. De todas formas, tras las airadas críticas de algunos eminentes autores, la doctrina reaccionó y comenzó a tomar más en cuenta la realidad de la Unión Europea ${ }^{6}$.

Por otra parte, desde que el Tratado de Maastricht acuñara el término «Unión Europea», la doctrina cuestionó la existencia o no de una personalidad jurídica de la Unión, es decir, si ésta existe como tal en el plano jurídico, si tiene capacidad de obrar, puede contraer obligaciones, es sujeto de responsabilidad,

4 Vide TOTH, A. G., «European Union» (1990), TOTH, A. G. (ed.), The Oxford Encyclopedia of Community Law, Vol. I, Institutional Law, OUP, London, p. 248.

5 Así, por ejemplo CRAIG, P., DE BÚRCA, G. (1995), EC Law - Text, Cases and Materials, Oxford University Press, London (la segunda edición, de 1998, cambiaba «EC Law» por «EU Law», aunque el contenido del libro es prácticamente el mismo, la tercera, de 2003 y la cuarta, de 2008 han introducido algunos cambios) o SIMON, D. (1997), Le système juridique communautaire, PUF, Paris (la segunda edición de 1998 y la tercera de 2001 corrigen esta carencia y realizan interesantes consideraciones sobre la personalidad jurídica de la UE, especialmente, en la 3. a ed., vide pp. 119-126). Aún hoy, algún eminente autor conserva este punto de vista, así, HARTLEY, T. C., (2007), The Foundations of European Community Law, 7th ed., University Press, Oxford.

${ }^{6}$ Especialmente, tras las duras críticas de DE WITTE, B. (1998), «The pillar structure and the nature of the European Union: Greek temple or French Gothic cathedral?», T. HEUKELS, N. BLOKKER, M. BRUS (eds.), The European Union after Amsterdam - A Legal Analysis, The Hague, Kluwer Law International, 1998, 51-68, pp. 57 y 58, muchos autores reaccionaron y levantaron el paréntesis en que habían colocado el Derecho de la Unión (vide supra, nota anterior). Muchos otros, sin embargo, materialmente siguieron ignorando la realidad de la UE y, simplemente, adoptaron unas siglas que, sin duda, han triunfado, y comenzaron a hablar de la Unión, aunque refiriéndose exclusivamente a la CE. Así, en este sentido y a modo de ejemplo, vide MISSIROLI, A. (2000), «PESC, défense et flexibilité», Cahiers de Chaillot, Vol. 38, pp. 1-60. 
etc., o, por el contrario, si ese nombre sólo hacía referencia a un concepto sin trascendencia jurídica directa que podría concretarse en las acciones concertadas de los Estados miembros. Así, las opiniones iban desde aquellos autores que negaban su personalidad jurídica, esgrimiendo que el apelativo hacía referencia a simples procedimientos de cooperación interestatales (KÖNIG, PECHSTEIN) hasta los que pensaban que sólo existía una organización, la UE, dentro de la cual se habían fusionado las Comunidades preexistentes (VON BOGDANDY, NETTESHEIM), extremos éstos entre los cuales hay todo un abanico de posibilidades intermedias con todo tipo de matices (vide infra).

\section{EL CONCEPTO DE PERSONALIDAD JURÍDICA EN LAS ORGANIZACIONES INTERNACIONALES}

5. La personalidad jurídica en el Derecho internacional implica la capacidad para ser titular de derechos y obligaciones ${ }^{7}$. Por regla general esa capacidad implica también la posibilidad de hacer valer estos derechos en el ámbito del derecho internacional (ius standi). Del concepto de subjetividad en Derecho internacional se debe separar la capacidad jurídica para actuar, la cual se encuentra por lo general vinculada a la personalidad jurídica, aunque no conceptualmen$\mathrm{te}^{8}$. Por otra parte, de la capacidad jurídica de Derecho internacional de una organización internacional se debe diferenciar la capacidad jurídica y contractual en el Derecho interno de los Estados miembros y de terceros Estados ${ }^{9}$. La personalidad jurídica de una organización internacional distingue a éstas de los simples fenómenos, casi siempre temporales, de cooperación interestatal y le

7 Para una explicación más exhaustiva del concepto de personalidad jurídica, subjetividad en Derecho internacional y capacidad jurídica de actuar, vide HERDEGEN, M. (2005), Derecho internacional público, Fundación Konrad Adenauer - UNAM, México, pp. 65-69.

${ }^{8}$ El Imperio Alemán, como sujeto del derecho internacional, no desapareció en todo caso con la disolución de los órganos competentes para actuar, ni por el hecho de que las potencias aliadas en junio de 1945 hubieran asumido la administración suprema del país. Estados como Somalia vieron mermada su capacidad de actuar hacia el exterior con la su presión efectiva del poder estatal, sin embargo siguieron existiendo como sujeto del derecho internacional.

9 De la capacidad jurídica y contractual de derecho interno depende el que una organización internacional en un Estado pueda adquirir inmuebles y otros bienes patrimoniales, celebrar contratos y en algunos casos desarrollar actividades de derecho privado. En muchos casos, la capacidad jurídica y contractual de una organización internacional en los Estados miembros individualmente, se encuentra reglamentada expresamente en el tratado de creación, al igual que la atribución de la personalidad jurídica, otras se les supone, de acuerdo con la doctrina de los implied powers que veremos a continuación. 
confiere una existencia jurídica distinta a la de sus Estados miembros. No obstante, observando la realidad actual, cada vez parece más confusa la línea divisoria entre un foro internacional de cooperación una organización internacional. Buena prueba de ello sería la transformación sufrida por la Conferencia de Seguridad y Cooperación en Europa, hasta convertirse en 1995 en Organización para la Seguridad y la Cooperación en Europa (OSCE).

6. Adoptando una definición más bien tradicional de organización internacional que considera a éstas como asociaciones de Estados, constituidas por un tratado internacional, dotadas de una constitución y de órganos comunes y con una personalidad jurídica distinta de la de sus Estados miembros, parece posible llegar a trazar esos perfiles diferenciadores ${ }^{10}$. Siguiendo a SCHERMERS y BLOKKER, podemos referirnos a tres escuelas de pensamiento en relación a la atribución de personalidad jurídica a organizaciones internacionales ${ }^{11}$. En primer lugar, según la teoría de la voluntad, para que una organización internacional goce de personalidad jurídica, es necesario que ésa sea la voluntad expresa de los Estados miembros. En segundo lugar, el enfoque de la personalidad objetiva exige la existencia de al menos un órgano en la organización con voluntad distinta a la de los Estados miembros. En este caso, la personalidad no es concedida por los Estados sino que se derivaría directamente del derecho internacional. En tercer lugar, puede existir una personalidad jurídica implícita, que existirá cuando la organización pueda actuar en la esfera externa. Klabbers ofrece una cuarta opción, la de la personalidad presunta, según la cual se presume la existencia de personalidad jurídica de la mera existencia de la organización, nacida de la voluntad de los Estados de atribuirle ciertas competencias ${ }^{12}$. Este último planteamiento se desprendería del dictamen de la Corte Internacional de Justicia de 1948 cuando afirmaba que «cincuenta Estados que representan a una gran mayoría de los miembros de la comunidad internacional tenían el poder, conforme

10 Sobre los elementos constitutivos y la naturaleza de las organizaciones internacionales, vide PASTOR RIDRUEJO, J. A. (2009), Curso de Derecho internacional Público y Organizaciones internacionales, 13. ${ }^{\mathrm{a}}$ ed., Tecnos, Madrid, pp. 657-665, quien distingue tres perspectivas para una aproximación al concepto de organización internacional: la técnico-jurídica, la histórico-social y la política.

11 SCHERMERS, H. G., BLOKKER, N. (2003), International Institutional Law, Martinus Nijhoff Publishers, Leyden, pp. 988-989. Sobre esta cuestión, puede verse así mismo VERWEY, D. (2004), The European Community, the European Union and the International Law of the Treaties, T. M. C. Asser Press, La Haya, p. 67.

12 KLABBERS, J. (1998), "Presumptive Personality: The European Union in International Law», KOSKENNIEMI, M. (ed.), International Law Aspects of the European Union, Martinus Nijhoff, La Haya, p. 231. 
al Derecho internacional, de crear una entidad con personalidad internacional objetiva y no simplemente una personalidad reconocida solamente por ellos» ${ }^{13}$. La mayor parte de la doctrina se inclina por una posición intermedia que presume la personalidad internacional de las organizaciones internacionales, presunción sometida a confirmación a través del tratado constitutivo, del que conviene hacer una lectura literal y teleológica, siguiendo los principios interpretativos recogidos por el Convenio de Viena sobre Derecho de los tratados de 1969 , en su artículo $31^{14}$.

7. La personalidad jurídica de las Organizaciones internacionales puede manifestarse en los ordenamientos nacionales y en Derecho internacional. La mayoría de los tratados constitutivos hacen referencia a la primera de estas manifestaciones, necesaria para que la organización pueda llevar a cabo actuaciones jurídicas en los distintos Estados miembros, tales como la adquisición de bienes, contrataciones o ius standi ante los tribunales internos ${ }^{15}$. Así, por ejemplo, la Carta de Naciones Unidas, en su artículo 104 reconoce esta capacidad jurídica de la Organización. Otro tanto ocurría con la Comunidad Europea. Así, además de tener expresamente reconocida la personalidad jurídica ex artículo $281 \mathrm{TCE}$, el artículo 282 TCE reconocía la más amplia capacidad jurídica de la Comunidad dentro de cada uno de los ordenamientos jurídicos de los Estados miembros.

Así descrita como categoría jurídica, esta personalidad interna de la organización sería oponible a sus Estados miembros, no a Estados terceros puesto que, aunque sea una realidad objetiva, la falta de reconocimiento por parte de éstos equivale a la negativa a aceptar su existencia jurídica ${ }^{16}$. Ahora bien, para atender

${ }^{13}$ Caso Reparación por daños sufridos al servicio de las Naciones Unidas, Opinión consultiva de la Corte Internacional de Justicia de 11 abril 1949, op. cit., p. 179.

${ }^{14}$ En este sentido, vide DUPUY, J. M. (1995), Droit international public, 3. ${ }^{\text {a ed., Dalloz, Pa- }}$ ris, pp. 162-166.

15 FERNÁNDEZ SOLA, N. (2002), "La subjetividad internacional de la Unión Europea», Revista de Derecho Comunitario Europeo, n. ${ }^{\circ} 11$, pp. 85-112, especialmente, pp. 87-88.

16 DORMOY, D. (1995), Droit des Organisations internationales, Dalloz, Paris, p. 36. Por otra parte, para la capacidad jurídica de una organización internacional en el Derecho interno de un tercer Estado, se debe tener en cuenta, ante todo, si este tercer Estado reconoce la personalidad jurídica también en la esfera del derecho privado (por ejemplo, en un acuerdo de constitución o de conformidad con las reglas de respectivo Derecho internacional privado). La Cámara de los Lores británica se ha negado a otorgarle personalidad jurídica a la sede de las organizaciones internacionales. Así, en Arab Monetary Fund vs. Hashim and others, Sentencia de la Cámara de los Lores de 21 febrero 1991, disponible en International Law Reports (1991), Vol. 85, p. 1. Para un comentario sobre este caso, vide KLABBERS, J. (2002), An Introduction to International Institutional Law, University Press, Cambridge, pp. 48-51. 
a la consideración de las organizaciones internacionales como sujetos de Derecho internacional hay que analizar, sobre todo, la manifestación internacional de su personalidad jurídica ${ }^{17}$. Más raramente se pueden encontrar menciones expresas al respecto en los tratados constitutivos, siendo el artículo 6 de la extinta Comunidad Europea del Carbón y el Acero (CECA) una de las raras excepciones a la tónica general. No obstante, y desde antiguo, la jurisprudencia internacional, aplicando la teoría de los poderes implícitos, ha venido reconociendo tal subjetividad internacional ${ }^{18}$.

8. Tomando nuevamente como ejemplo la Carta de Naciones Unidas, sus artículos 57 y 63 reconocen a la Organización la capacidad para concertar tratados con instituciones especializadas; los artículos 26 y 43 autorizan al Consejo de Seguridad a concertar ciertos tratados con los Estados miembros, y, finalmente, los artículos 75, 77 y 79 prevén la concertación de los acuerdos de administración fiduciaria entre la Organización y los Estados interesados. Así pues, como ha señalado la doctrina respecto de esta organización, siendo la capacidad de concluir tratados internacionales una de las consecuencias de la personalidad internacional, sin más elementos de juicio que el texto de los citados artículos y la práctica convencional desarrollada en su aplicación, podría llegarse a la conclusión de la existencia de personalidad internacional de la Organización y a la posibilidad de que también se pueda atribuir a otras organizaciones internacionales el mismo carácter de sujeto de Derecho internacional $^{19}$.

La opinión consultiva de la Corte Internacional de Justicia, de 11 de abril de 1949, confirmó la personalidad internacional de la Organización universal y dejó sentadas las bases para verificar la situación de las restantes Organizaciones internacionales. La definición de personalidad jurídica internacional dada por la Corte en este famoso dictamen es una definición funcional: en la medida en que las funciones asignadas a la Organización no podrían verse realizadas sin una ac-

17 Sobre este particular, vide JENKS, W. (1945), «The Legal Personality of International Organisations», British Yearbook of International Law, Vol. 16, pp. 267-275; RAMA MONTALDO, M. (1970), «International Legal Personality and Implied Powers or International Organizations», British Yearbook of International Law, Vol. 41, pp. 111-155; PÉREZ GONZÁLEZ, M. (1998), «Les Organisations internationales et le droit de la responsabilité», Revue Générale de Droit International Public, Vol. 92/1, pp. 63-102.

18 BROWNLIE, I. (2003), Principles of Public International Law, 6th ed., University Press, Oxford, pp. 648-650.

19 MIAJA DE LA MUELA, A. (1979), Introducción al derecho internacional público, 7. a ed., Madrid, pp. 206-209. 
tuación en el ámbito internacional, dicha subjetividad está implícita en tales funciones $^{20}$. Aquí reside, como es sabido, la diferencia entre la subjetividad internacional de los Estados y la de las organizaciones internacionales. Mientras que los primeros disponen de la totalidad de derechos y obligaciones internacionales (lo que la doctrina denomina personalidad jurídica internacional plena) pues son entes soberanos, las organizaciones solamente disponen de aquellas competencias atribuidas por los Estados para la realización de sus funciones que son las que perfilan el contenido exacto de su personalidad internacional siendo ésta, por tanto, una personalidad funcional y limitada ${ }^{21}$. Por esta razón, la extensión de los derechos y obligaciones en virtud de su subjetividad internacional varía de una organización internacional a otra ${ }^{22}$.

\section{LA CONTROVERTIDA PERSONALIDAD JURÍDICA INTERNACIONAL DE LA UNIÓN EUROPEA}

9. ¿Qué implica tener personalidad jurídica? ¿Qué implicaría para la UE tener personalidad jurídica? Al margen de las consideraciones sobre la propia existencia y características de la Unión Europea como una entidad política, más propias de un análisis politológico de la Unión, resulta de interés para los

20 Caso Reparación por daños sufridos al servicio de las Naciones Unidas, Opinión consultiva de la Corte Internacional de Justicia de 11 abril 1949, op. cit., pp. 179-180. Para un análisis de esta cuestión, vide GAUTIER, P. (2000), "The Reparation for Injuries Case Revisited: The Personality of the European Union", FROWEIN, J. A.; WOLFRUM, R. (eds.), Max Planck Yearbook of United Nations Law, Vol. 4, pp. 331-361, especialmente 337-341.

${ }^{21}$ En este sentido se han expresado los Estados miembros de la Unión Europea en la Declaración n. ${ }^{\circ} 24$ aneja al Tratado de Lisboa, cuando afirman que el hecho de que la Unión disponga de personalidad jurídica no implica que pueda legislar o actuar más allá de las competencias que le han atribuido los Estados mediante los Tratados.

22 REUTER, P. (1975), Institutions internationales, Themis, París, p. 273; HERDEGEN, M., Derecho internacional público, op. cit., p. 69. Sobre este particular, la profesora FERNÁNDEZ SOLA ha criticado duramente el Informe Alber, que se aprobó oficialmente por el Parlamento Europeo como Resolución sobre las relaciones entre el Derecho internacional público, el Derecho comunitario y el Derecho constitucional de los Estados miembros, A-4.0278/97, Diario Oficial de las Comunidades Europeas, C 325, de 27 octubre 1997. Dicho informe proponía en su punto 14 una «equiparación de la CE a los Estados nacionales» en la «cuestión de la relación entre el Derecho internacional y el Derecho europeo» en el sentido de que «el Derecho internacional no sea aplicable directamente, sino sólo una vez que haya sido declarada su aplicabilidad a través de un acto jurídico interno de la $\mathrm{CE}$ o tras la transformación de su contenido en formas jurídicas del Derecho comunitario». En este sentido, vide FERNÁNDEZ SOLA, N. (2002), «La subjetividad internacional de la Unión Europea», op. cit., pp. 89-90. 
objetivos de este trabajo realizar algunas consideraciones sobre la naturaleza jurídica de la misma, es decir, sobre cuestiones tales como su existencia misma en el plano jurídico-internacional, como sujeto capaz de asumir derechos y obligaciones $^{23}$. Como se ha visto, cuando se dota a una organización internacional de personalidad jurídica, ésta adquiere una existencia jurídica distinta de la de sus Estados miembros y puede actuar y comportarse de manera diferente a ellos, en función de las competencias que posea. Por otra parte, es conveniente no olvidar que el hecho de dotar expresamente a una organización de personalidad jurídica no condiciona ni determina, en absoluto, la extensión de sus derechos y obligaciones ${ }^{24}$.

10. Sin negar la especificidad y originalidad de las Comunidades Europeas, especialmente en lo que a su naturaleza política se refiere, no hay que olvidar que constituyen una creación jurídica internacional y el fundamento de su existencia y, en buena medida, los condicionamientos de su evolución, residen en el Derecho internacional. En virtud del artículo 281 del Tratado constitutivo de la Comunidad Europea y del artículo 184 del Tratado constitutivo de la Comunidad Europea de la Energía Atómica, ambas, la Comunidad Europea y la Comunidad Europea de la Energía Atómica tenían reconocida expresamente personalidad jurídica. Centrando la cuestión en las Comunidades Europeas como fenómeno asociativo dentro del Derecho internacional, su personalidad internacional ha sido confirmada por el Tribunal de Justicia de las Comunidades Europeas, con base en determinadas disposiciones de los Tratados constitutivos y en las funciones asignadas que exigen una presencia internacional ${ }^{25}$. Esto significa que las Comunidades pueden, en principio, concluir acuerdos con terceros Estados y con organizaciones internacionales, participar en dichas organizaciones ${ }^{26}$, estar sujetas a responsabilidad según el Derecho internacional si incumplen sus

${ }^{23}$ Para un análisis politológico de la Unión Europea y, más ampliamente, del fenómeno de la integración europea, vide MARISCAL BERÁSTEGUI, N. (2003), Teorías políticas de la integración europea, Tecnos, Madrid.

${ }^{24}$ Así, vide RAUX, J. (1966), Les relations extérieures de la Communauté économique européenne, Cujas, Paris, p. 42.

25 En general, sobre la personalidad jurídica internacional de las Comunidades y el caso de la Unión, vide LENAERTS, K., VAN NUFFEL, P., BRAY, R. (2005), Constitutional Law of the European Union, 2. ${ }^{\text {e }}$ ed., pp. 815-818.

${ }^{26}$ Sobre esta cuestión, vide SACK, J. (1996), «The European Community's membership of international organizations», Common Market Law Review, Vol. 32/5, pp. 1227-1256 y NEUWAHL, N. A. (1996), «Shared powers or combined incompetence?: more on mixity», Common Market Law Review, Vol. 33/4, pp. 667-687. 
obligaciones y emprender por sí mismas las acciones pertinentes en caso de que sus derechos sean infringidos. Tal reconocimiento, en todo caso, no implica que el contenido y alcance de esa personalidad no plantee problemas jurídicos debido a la singularidad de aquéllas como modelo de organización, que se manifiesta particularmente en el ámbito de las relaciones exteriores y la representación internacional ${ }^{27}$.

\subsection{La discutida personalidad internacional de la Unión Europea}

11. La claridad, y menos aún la unanimidad doctrinal (que por otra parte encontraría serias dificultades para plantarse frente a la contundencia del artículo 281 TCE) con la que se manifiesta la subjetividad internacional de las Comunidades Europeas no existe a la hora de realizar una valoración análoga de la Unión Europea. La cuestión de saber si tiene o no personalidad jurídica interna no es asunto que revista las mayores consecuencias. Ciertamente, aun cuando es necesario la realización de los objetivos explicitados en el Tratado de la Unión, se recurre a la Comunidad y a la capacidad expresa de ésta sobre el plano interno para realizar actos jurídicos en el territorio de los Estados miembros ${ }^{28}$. Por el contrario, sí que ha suscitado numerosas controversias, como se verá, la eventual afirmación de su subjetividad internacional. Llegados a este punto, conviene evitar centrarse en una discusión meramente terminológica e intentar aprehender el interés práctico de la cuestión de la personalidad internacional de la UE, es decir, simplificar la descripción de los fenómenos jurídicos (o políticos con claras consecuencias jurídicas). En este sentido, el contenido material de la personalidad internacional se centra en la existencia de competencias externas reales y en una cierta autonomía financiera de la organización, aspectos ambos que se tendrá en cuenta en el análisis subsiguiente.

27 Así lo constatan MANGAS MARTÍN, A. y LIÑÁN NOGUERAS, D. J. (2004), Instituciones y Derecho de la Unión europea, 4. ${ }^{\mathrm{a}}$ ed., Tecnos, Madrid, pp. 625-627. Igualmente, subrayando las dificultades técnico-políticas que se han opuesto al ejercicio por la Comunidad Europea de su subjetividad internacional, particularmente a su participación en foros y convenios multilaterales, vide ROLDÁN BARBERO, J. (1998), «La participación de la Unión Europea en organismos internacionales», MARIÑO, F. (ed.), Acción exterior de la UE y comunidad internacional, BOE, Madrid, pp. 243-271. Vide infra, el caso de la participación en la «Comisión de Consolidación de la Paz de Naciones Unidas».

${ }^{28}$ BRIBOSIA, E., WEYEMBERGH, A. (1999), «La personnalité juridique de l'Union européenne», DONY, M. (coord.), L'Union Européenne et le monde après Amsterdam, Éditions de l'Université, Bruxelles, pp. 37-60, especialmente, p. 41. 
12. A diferencia de lo que preveía el proyecto de Tratado de la Unión Europea elaborado por el Parlamento Europeo en 1984, el Tratado de Maastricht que instituyó la UE no hacía referencia expresa a la personalidad de la Unión $^{29}$. No obstante, ello no implicaba forzosamente su inexistencia, pues, como se ha visto, aquélla puede atribuirse de manera implícita. Para ello, ante la oscuridad del texto del TUE y al objeto de determinar la voluntad subjetiva de los Estados negociadores, la mayoría de los autores, siguiendo criterios interpretativos clásicos del Derecho internacional, acudió a los trabajos preparatorios del TUE, los cuales demuestran la existencia de opiniones enfrentadas de dichos Estados y de las instituciones comunitarias al respecto ${ }^{30}$. Ahora bien, la interpretación derivada de tales trabajos preparatorios tampoco llevaría sin más a descartar la existencia de personalidad internacional implícita de la UE, pues el Derecho internacional general limita la validez de este medio de interpretación de los tratados internacionales. En efecto, el tratado, en este caso el Tratado de la Unión Europea, es una realidad objetiva fruto del compromiso surgido de una negociación internacional en la que las posturas divergentes han ido convergiendo hacia puntos de encuentro. Por ello, el Convenio de Viena sobre Derecho de los Tratados de 1969, que codifica las reglas interpretativas de los tratados en sus artículos 31 y 32, relega la utilización de los trabajos preparatorios a medio complementario de interpretación al que tan sólo se podrá acudir para confirmar la interpretación obtenida por los medios prioritarios o si el resultado obtenido de éstos es confuso o irrazonable. Por ello, y siguiendo la pauta dada por el artículo 31 del Convenio de Viena, para la interpretación del Tratado de la Unión Europea en este punto habría que acudir al tenor literal del mismo o a la voluntad de las partes en él implícita o manifestada por su práctica ulterior.

13. De este modo, no habiendo disposición expresa al respecto, algunos autores quisieron deducir la personalidad internacional de la UE del articulado del

29 El Proyecto de Tratado de la Unión Europea o «Proyecto Spinelli», de 1984, en su artículo 6 atribuía expresamente personalidad jurídica internacional e interna a la Unión Europea, al tiempo que desaparecía la subjetividad de las actuales tres Comunidades Europeas. El texto del proyecto del Tratado y la Resolución pueden consultarse, por ejemplo, en Revista de Instituciones Europeas (1984), n.o 1, pp. 351-377.

30 BRIBOSIA E., WEYEMBERGH, A. (1999), «La personnalité juridique de l'Union européenne», op. cit., pp. 44-45, especialmente, vide la extensa nota a pie de página 34, p. 44. Para una completa y detallada narración de los trabajos preparatorios, vide CLOOS, J., REINESCH, G., VIGNES, D. (1993), Le Traité de Maastricht: genèse, analyse, commentaires, Bruylant, Bruxelles. 
texto del tratado o de la existencia de órganos propios de la Unión ${ }^{31}$. Así, entre las disposiciones del Tratado en las que se encontraría un reconocimiento implícito de la subjetividad internacional de la Unión Europea, se suelen citar el último párrafo del preámbulo o los artículos 1 (antiguo artículo A) y 6 (antiguo artículo F) del Tratado de la Unión Europea. En el primero, las Altas Partes Contratantes declaraban instituir entre ellas una Unión Europea, mientras que en el artículo 6 la hacían acreedora de determinadas obligaciones (respetar la identidad de sus Estados miembros y los derechos fundamentales) que constituían obligaciones internas asumidas frente a los Estados miembros, no de carácter internacional o que obliguen unilateralmente a la Unión frente a terceros Estados.

14. El artículo 2 del TUE (antiguo artículo B), por su parte, establecía los objetivos propios de la UE, distintos de los de las Comunidades Europeas, y entre los que figuraba la afirmación de su identidad en la escena internacional,

31 Entre ellos, CHARPENTIER, J. (1995), «De la personnalité juridique de l'Union Européenne», GALABERT, J. M., TERCINET, M. R., Mélanges en l'honneur du professeur Gustave Peiser, Presses, Grenoble, pp. 93-102, especialmente, pp. 96-97. Igualmente, después de Amsterdam, aunque analizando la eventual personalidad en Maastricht, TIZZANO, A. (1999), «La personnalité internationale de l'Union Européenne», DONY, M., DE WALSCHE, A., WAELBROECK, M. (eds.), Mélanges en hommage à Michel Waelbroeck, Bruylant, Bruxelles, Vol. I, pp. 169-204, especialmente, pp. 189-196. Pero, sin duda, fue la doctrina germana, la que con mayor entusiasmo se pronunció en este sentido, así, DÖRR, O. (1995), "Zur Rechtsnatur der Europäischen Union», Europarecht, Vol. 30/4, pp. 334-348; VON BOGDANDY, A., NETTESHEIM, M. (1996), «Die Europäische Union: Ein einheitlicher Verband mit eigener Rechtsordnung», Europarecht, Vol. 31/1, pp. 3-26, traducido y publicado en inglés como VON BOGDANDY, A., NETTESHEIM, M. (1996), «Ex Pluribus Unum: Fusion of the European Communities into the European Union", European Law Journal, Vol. 2/3, pp. 267-289. De la misma forma, RIDEAU, J. (1996), Droit institutionnel de l'Union et des Communautés Européennes, LGDJ, Paris, que habla de una "personnalité embryonnaire» de la Unión; MANGAS MARTÍN, A. y LIÑÁN NOGUERAS, D. J. (2004), Instituciones y Derecho de la Unión europea, op. cit., pp. 68-69, donde cita un informe del servicio jurídico del Consejo en el mismo sentido (Comments on the draft amendments to Article 24 TEU, SN 5332/1/00 REV 1, de 24 de noviembre de 2000), JACQUÉ, J. P. (2006), Droit institutionnel de l'Union Européenne, 4. ${ }^{\mathrm{a}}$ ed., Dalloz, Paris, pp. 164-166. En contra del reconocimiento de la personalidad la Unión, entre otros, PECHSTEIN, M., KÖNIG, C. (1998), Die Europäische Union: Die Verträge von Maastricht und Amsterdam, Mohr Siebeck, Tübingen, especialmente, p. 21; PECHSTEIN, M. (1996), "Une personnalité internationale pour l'Union européenne», Revue des Affaires Européennes, Vol. 3, pp. 229-233; EVERLING, U. (1992), "Reflections on the structure of the European Union", Common Market Law Review, Vol. 29/6, pp. 1053-1078; PLIAKOS, A. (1993), «La Nature juridique de l'Union Européenne», Revue Trimestrielle de Droit Européen, Vol. 29/2, pp. 187-224; incluso el Tribunal Constitucional Alemán en su célebre sentencia Maastricht de 12 octubre 1993 (BVerfGE 89, 155 - Maastricht Urteil), vide infra. 
aunque hay quien sostiene el término «identidad» revestiría aquí un sentido socio-político, que no jurídico ${ }^{32}$.

15. También el artículo 18 del TUE (antiguo artículo J.1) asignaba a la UE los objetivos de la política exterior y de seguridad común y le atribuía a la presidencia del Consejo la representación de la UE en asuntos dependientes de dicha política. Aunque es cierto que, como señala CHARPENTIER, resulta difícil conciliar la existencia de la regulación de la PESC con la ausencia de personalidad internacional, por sí sola no constituiría un argumento decisivo si se entiende que los objetivos de la UE en este terreno podían ser alcanzados por la acción coordinada de sus Estados miembros a título intergubernamental ${ }^{33}$. De esta opinión, son partidarios KÖNIG y PECHSTEIN, quienes no sólo negaban que la UE fuese una organización internacional, sino que argumentaban que el apelativo «Unión Europea» no era más que una manera de describir el particular modo de cooperación interestatal recogido en los Títulos V y VI del Tratado de la Unión. Consecuentemente, las decisiones adoptadas por el Consejo en las áreas del segundo y tercer pilar habrían de ser consideradas como acuerdos internacionales entre los Estados miembros ${ }^{34}$.

Esta opinión refleja a la perfección las consideraciones del Tribunal Constitucional Federal alemán en su famosa sentencia de 12 de octubre de 1993, conocida como caso Maastricht. Esta decisión, que finalmente permitió la ratificación del Tratado de Maastricht por Alemania, entre otras cosas, determinó la ausencia de personalidad jurídica de la Unión. Efectivamente, el Bundesverfassungsgericht declararía:

«[E]l Tratado de la Unión no deja vislumbrar en ningún lugar la unánime voluntad de las partes contratantes de dar a la fundación de esta Unión el carácter de sujeto jurídico autónomo, que sea titular de competencias propias. A juicio del Gobierno Federal, la Unión carece de personalidad jurídica aparte en relación tanto con las Comunidades Europeas cuanto con los Estados miembros. (...) El Tratado de la Unión entiende ahí a la Unión no ya como sujeto jurídico autó-

32 BRIBOSIA E., WEYEMBERGH, A. (1999), «La personnalité juridique de l'Union européenne», op. cit., p. 46. Curiosamente, el Tratado de Lisboa relega al preámbulo del Tratado de la Unión Europea el reforzamiento de la identidad de ésta como tarea de la política exterior y de seguridad común de la Unión.

33 CHARPENTIER, J. (1995), «De la personnalité juridique de l'Union Européenne», op. cit., pp. 96-100.

34 PECHSTEIN, M., KÖNIG, C. (1998), Die Europäische Union: Die Verträge von Maastricht und Amsterdam, op. cit., pp. 63 y 177. Igualmente, PECHSTEIN, M. (1996), «Une personnalité internationale pour l'Union européenne», op. cit., pp. 229-233. 
nomo, sino como denominación aplicable a los Estados miembros que actúan en común; éstos dotan convencionalmente a la Unión de objetivos y medios» ${ }^{35}$.

En el mismo sentido se expresó la Comisión especial para las Comunidades Europeas de la House of Lords'.

16. Finalmente, el artículo 49 del TUE se refería a la adhesión de nuevos miembros a la Unión Europea, no a las tres Comunidades Europeas, lo que, para algunos, sería determinante de la personalidad internacional de aquélla. También aquí, BRIBOSIA y WEYEMBERGH afirman que lo que este precepto está contemplando es la adhesión de nuevos Estados al Tratado de la Unión Europea, no a la Unión Europea como Organización con personalidad propia ${ }^{37}$. Radicalmente en contra se pronuncian, entre otros TIZZANO y DE WITTE, para quien dicho artículo «define la pertenencia al club como pertenencia a la Unión Europea ${ }^{38}$. Parece a todas luces correcto afirmar que el artículo 49 del Tratado de

35 Sentencia del Tribunal Constitucional alemán, de 12 octubre 1993, BVerfGE 89, 155 (195). Maastricht Urteil, 2 BvR 2134/92 u. 2159/92, BVerfGE 89, 155, (155-213). Existe una traducción en español publicada en Boletín de Jurisprudencia Constitucional, núm. 153, 1994, pp. 183-203. Más recientemente, se ha publicado otra traducción de esta sentencia en ALÁEZ CORRAL, B., ÁLVAREZ ÁLVAREZ, L. (2008), Las decisiones básicas del Tribunal Constitucional Federal alemán en las encrucijadas de cambio de milenio, BOE-CEPC, Madrid, pp. 222-281. Para un comentario de la Sentencia, vide HERDEGEN, M. (1994), «Maastricht and the German Constitutional Court: Constitutional restraints for "an ever closer Union”", Common Market Law Review, Vol. 31/2, pp. 235-249; EVERLING, U. (1994), «The Maastricht Judgment of the German Federal Constitutional Court and its Significance for the Development of the European Union», Yearbook of European Law, Vol. 14, pp. 1-19; HAILBRONNER, K. (1995), "The European Union from the Perspective of the German Constitutional Court», German Yearbook of International Law, Vol. 37, pp. 93-112.

${ }^{36}$ HOUSE OF LORDS, Select Committee on the European Communities, citado por NEUWHAL, N. (1998), «A Partner With a Troubled Personality: EU Treaty-Making in Matters of CFSP and JHA after Amsterdam", European Foreign Affairs Review, Vol. 3/2, pp. 177-196, la cita aparece en la p. 180.

37 BRIBOSIA E., WEYEMBERGH, A. (1999), «La personnalité juridique de l'Union européenne», op. cit., p. 46. De esta opinión es, también, FERNÁNDEZ SOLA, N. (2002), «La subjetividad internacional de la Unión Europea», op. cit., p. 95, quien fundamenta su parecer en el artículo 15 del Convenio de Viena y en el Derecho internacional general, "por cuanto, los nuevos Estados deben ratificar un tratado internacional ya vigente, el TUE, que formalmente engloba a los tres tratados constitutivos de las Comunidades Europeas más los ámbitos de cooperación intergubernamental de los Estados representados por el segundo y tercer pilar de la UE».

38 Vide DE WITTE, B. (1998), "The pillar structure and the nature of the European Union: Greek temple or French Gothic cathedral?», HEUKELS, T., BLOKKER, N., BRUS, M. (eds.), The European Union after Amsterdam: a legal analysis, Europa Institute, Leiden University, 
la Unión contribuía a sustentar las tesis DE WITTE quien, a su vez, se basa en la teoría de la «unidad» (unity) que la doctrina ha desarrollado y según la cual la Unión Europea quedaría configurada como un todo dotado de personalidad jurídica en cuyo seno quedarían asimiladas (fusionadas, merged en inglés) las personalidades de las otras comunidades (y de otras instituciones de la Unión, como el Banco Central), de tal forma que toda actuación de las Comunidades sería una actuación de la Unión que, instrumentalmente, opera a través de ellas ${ }^{39}$. Por otro lado, y en relación con este punto, algunos autores opinan que el hecho de que el Tratado de adhesión lo firman los Estados ya miembros y no la propia Unión Europea abonaría la tesis de la falta de personalidad jurídica de ésta ${ }^{40}$. El argumento pierde toda su fuerza cuando se observa que, tras la reforma operada por el Tratado de Lisboa y la atribución expresa de personalidad jurídica a la Unión (art. 47 TUE-L), siguen siendo los Estados miembros, y no la Unión, los que firman el tratado de adhesión de nuevos socios (art. 49 TUE-L) ${ }^{41}$.

17. Si como base de la argumentación se adopta la aproximación clásica a la subjetividad internacional, los resultados son parcialmente análogos. Según este concepto de subjetividad internacional, ésta confiere tres capacidades específicas: el treaty-making power o capacidad convencional, el establecimiento de relaciones diplomáticas y la participación en los mecanismos de responsabilidad internacional ${ }^{42}$. La práctica de la Unión Europea con el Tratado de

p. 59. Igualmente, TIZZANO, A. (1999), «La personnalité internationale de l'Union Européenne», op. cit., pp. 191-193.

39 Sobre la teoría de la «unidad», vide VON BOGDANDY, A., NETTESHEIM, M. (1996), «Ex Pluribus Unum: Fusion of the European Communities into the European Union», op. cit., pp. 267-289; DE WITTE, B. (1998), «The pillar structure and the nature of the European Union: Greek temple or French Gothic cathedral?», op. cit., pp. 58-64, para quien Ámsterdam no haría sino confirmar que las Comunidades son «sub-organizaciones» insertas en la UE, p. 62; igualmente, refiriéndose al "carácter unitario del sistema», vide TIZZANO, A. (1999), "La personnalité internationale de l'Union Européenne», op. cit., pp. 191-193. Más adelante, el mismo autor, se refiere a la Unión «como entidad autónoma», p. 192.

40 PECHSTEIN, M., KÖNIG, C. (1998), Die Europäische Union: Die Verträge von Maastricht und Amsterdam, op. cit., p. 42.

${ }^{41}$ Resulta curioso que, por el contrario, cuando se trata de la firma del Tratado por el que un Estado miembro abandonaría la Unión, sea el Consejo en nombre de la Unión y no los otros Estados miembros quien celebre el tratado (art. 50.1 TUE-L).

42 Vide DOMINICÉ, C. (1996), «La personnalité juridique dans le système du droit des gens", MAKARCZYK, J., Theory of International Law at the Threshold of the 21st Century - Essays in Honour of Krzysztof Skubiszewski, The Hague, Kluwer, pp. 147-171, especialmente, pp. 170 y 171. 
Maastricht no demuestra claramente la existencia o inexistencia de tales capacidades y tiene un carácter ambiguo, confuso, que denota la falta de voluntad política frente a una necesidad jurídica. Así, junto a indicios meramente nominativos tales como el cambio de denominación del Consejo o de las representaciones estatales acreditadas ante la UE, destaca la conclusión de instrumentos jurídicos cuya calificación de «tratado internacional» es dudosa, como también lo es el título de participación en ellos de la UE y de sus Estados miembros.

El ejemplo más evidente de todo ello es el Memorándum de acuerdo sobre la administración de Mostar, firmado el 5 de julio de 1994. Dicho acuerdo, calificado por algún autor de strange instrument, fue firmado «por los Estados miembros de la Unión Europea actuando en el marco de la Unión en estrecha asociación con la Comisión Europea y con los Estados miembros de la UEO", por los tres miembros de la troïka de la UE, un miembro de la Comisión y la presidencia de la UEO, por una parte, y por las autoridades de la república y de la federación de Bosnia-Herzegovina, las de la administración local de Mostar Este y Oeste y por los representantes croatas de Bosnia, de otra ${ }^{43}$. Según algunos autores, se deduce de los términos utilizados en el Memorándum que la Unión, como tal, no es parte del acuerdo y que, en consecuencia, los interlocutores sobre el plano internacional son los Estados miembros, con lo que no constituye una obligación internacional de la que se pueda deducir la personalidad de la $\mathrm{UE}^{44}$. Resultaría más interesante, no obstante lo anterior, centrarse en un aspecto del Memorándum, que es el de la cuestión económica, es decir, quién asumía el coste de las acciones derivadas del acuerdo. Cargar en el presupuesto de una organización internacional los gastos resultantes de una de sus actividades es, en efecto, un signo de que esa actividad le es imputable y, en consecuencia, de que dispone de personalidad. Así, en el caso de la Administración de Mostar, algunos gastos fueron cubiertos por el presupuesto comunitario mientras que otros quedaron a cargo de los Estados. Por otra parte, lo que era el «Presupuesto de las Comunidades Europeas» pasó a denominarse, tras el Tratado de Maastricht, «Presupuesto de la Unión». La solución parece quedar en terreno de nadie, y la opinión personal de cada comentarista pesará, sin duda, sobre el diagnóstico ulterior. De todas formas, no

43 El Memorándum está publicado en Boletín de la Unión Europea (1993), núm. 6, punto 1.3.6. Vide DASHWOOD, A. (1998), «External relations provisions of the Amsterdam Treaty», Common Market Law Review, Vol. 35/5, pp. 1019-1045.

44 BRIBOSIA, E., WEYEMBERGH, A. (1999), «La personnalité juridique de l'Union européenne», op. cit., p. 52. 
es muy descabellado apuntar que, si bien éste no es un elemento determinante, sí puede ser incluido dentro de los indicios de una personalidad latente de la $\mathrm{UE}^{45}$.

18. Como se ve, en el Tratado de Maastricht, la subjetividad de la UE no aparece clara. De hecho, la mayoría de los autores la rechazaron inicialmente y no se la plantearon seriamente hasta Ámsterdam ${ }^{46}$. Y es en las discusiones mantenidas al respecto en la CIG que daría lugar al Tratado de Ámsterdam donde ven el argumento definitivo para negar esa subjetividad ${ }^{47}$. En ellas, se puso de relieve por los distintos actores participantes los inconvenientes derivados de la falta de personalidad internacional de la Unión Europea y la necesidad de su atribución por parte del nuevo Tratado ${ }^{48}$.

Tanto el Consejo como el Parlamento Europeo y la mayoría de Estados miembros se mostraron favorables a un reconocimiento de personalidad internacional a la Unión Europea para hacer frente a las necesidades del entorno internacional contemporáneo ${ }^{49}$. No obstante, las presiones de algunos Estados (Reino Unido, Francia y Dinamarca) e incluso de la Comisión (que con la reafirmación de la personalidad internacional temía perder competencias) hicieron que, al final, desapareciera del texto definitivo del tratado modificativo del TUE la declaración expresa de la personalidad de la Unión ${ }^{50}$.

Nuevamente hay que recurrir a los anteriores criterios de interpretación para descubrir si, implícitamente, el tratado surgido de Ámsterdam contiene tal

45 De similar opinión es CHARPENTIER, J. (1995), «De la personnalité juridique de l'Union Européenne», op. cit., pp. 100-101.

46 Entre los partidarios de reconocer la subjetividad de la UE en Maastricht, por ejemplo, vide DE WITTE, B. (1998), «The pillar structure and the nature of the European Union: Greek temple or French Gothic cathedral?», op. cit., TIZZANO, A. (1999), «La personnalité internationale de l'Union Européenne», op. cit., quien, la defiende incluso desde el Acta Única Europea, p. 174, vide VON BOGDANDY, A., NETTESHEIM, M. (1996), «Ex Pluribus Unum: Fusion of the European Communities into the European Union», op. cit.

${ }^{47}$ Así, FERNÁNDEZ SOLA, N. (2002), «La subjetividad internacional de la Unión Europea», op. cit., pp. 96-97.

48 Sobre esta cuestión, vide el informe del Consejo ante la conferencia de representantes de los gobiernos de los Estados miembros, Personnalité juridique de l'Union, CONF/3871/96, de 16 de julio de 1996.

49 Informe del Grupo de Reflexión sobre la CIG '96, presentado en Bruselas el 5 de diciembre de 1995, SN 520/95, también llamado Informe Westendorp, $\$ 150$.

${ }^{50}$ Una descripción de las distintas propuestas y críticas de las mismas puede verse en DASHWOOD, A. (1998), "External relations provisions of the Ámsterdam Treaty», op. cit., pp. 1019-1045. 
reconocimiento. En este sentido, algunos autores han propuesto aplicar a la UE los criterios establecidos por la Corte Internacional de Justicia en su dictamen de 1949 para determinar la personalidad internacional implícita de la Organización de las Naciones Unidas (vide supra). Es decir, verificar que la misma es indispensable para la realización de los fines de la Organización, que ésta tiene órganos y competencias propios, si los Estados miembros están obligados a asistir a la Organización y, finalmente, si todo ello viene confirmado por la práctica ${ }^{51}$. De esta manera, BLOKKER y HEUKELS concluyen que la personalidad jurídica de la Unión, a pesar de ser «expresamente rechazada» (por los líderes europeos en Ámsterdam), resulta «implícitamente» aceptada. A pesar de que algunos autores hayan criticado esta vía para demostrar la personalidad de la UE, el análisis de los citados autores resulta bastante convincente y su conclusión de lo más acer$\operatorname{tada}^{52}$.

19. Con independencia de que otras disposiciones pudiesen jugar en el mismo sentido, sin lugar a dudas las disposiciones más reveladoras de las atribuciones realizadas en este terreno a la Unión Europea se encontraban en los artículos 24 y 38 TUE que conferían a la Unión el treaty-making power, si bien con determinadas condiciones. Concretamente, permitían al Consejo, cuando fuese preciso para la realización de los objetivos de la Política Exterior y de Seguridad Común o los del tercer pilar, concluir acuerdos con terceros Estados y con organizaciones internacionales ${ }^{53}$.

La cuestión que planteaba el artículo 24 del TUE era la de determinar si consagraba realmente la capacidad convencional de la Unión Europea, atributo particular de la personalidad jurídica internacional. El argumento utilizado para negarlo es que se estaría reconociendo a la Unión un poder de actuar in-

${ }^{51}$ BLOKKER, N., HEUKELS, T. (1998), «The European Union: historical origins and institutional challenges», HEUKELS, T., BLOKKER, N., BRUS, M. (eds.), The European Union after Amsterdam: a legal analysis, Europa Institute, Leiden University, pp. 31 a 36. En el mismo sentido, vide KLABBERS, J. (1998), «Presumptive Personality: The European Union in International Law», KOSKENNIEMI, M., International Law Aspects of the European Union, Kluwer, The Hague, pp. 231-253.

52 BLOKKER, N.M HEUKELS, T. (1998), «The European Union: historical origins and institutional challenges», op. cit., p. 36. En contra, aunque sin esgrimir ningún argumento, se muestra FERNÁNDEZ SOLA, N. (2002), «La subjetividad internacional de la Unión Europea», op. cit., p. 97.

53 Sobre estas bases legales, su uso y sus problemas, WESSEL, R. (2007), "Legal responsibility for agreements concluded by the European Union», FORNET CFSP Forum, Vol, 5/5, pp. 10-12. 
ternacionalmente como mandataria de los Estados miembros ${ }^{54}$. Este argumento quizá haya perdido peso tras la eliminación por el Tratado de Ámsterdam de la referencia a los Estados miembros del artículo 11 TUE. Si el artículo J.1.1 TUE en su redacción de Maastricht afirmaba que la Unión y sus Estados miembros definirían y realizarían una política exterior y de seguridad común, la versión de este precepto surgida de la CIG de 1996 (artículo 11.1 TUE) atribuyó esa tarea tan sólo a la Unión, por lo que, cuando ésta concluyese un tratado en virtud del nuevo artículo 24 TUE, lo haría en su nombre, no en el de los Estados miembros. Asimismo, de querer indicar que el acuerdo se concluía en nombre de los Estados miembros, la fórmula que se hubiese utilizado hubiese sido la de «los representantes de los Gobiernos de los Estados miembros reunidos en el seno del Consejo», y no la atribución a esta institución de la UE del poder de concluir tales acuerdos. Además, tanto el preámbulo como el artículo 24, párrafo 6 se referían a las «instituciones de la Unión Europea»"

54 De esta opinión, PECHSTEIN, M., KÖNIG, C. (1998), Die Europäische Union: Die Verträge von Maastricht und Ámsterdam, op. cit., pp. 120-141. Igualmente, MONAR, J. (1997), "The European Union's Foreign Affairs system after the Treaty of Amsterdam: a strengthened capacity for external action?», European Foreign Affairs Review, Vol. 2, pp. 413-436, en concreto, vide p. 416. Una posición más compleja sería la de LEAL-ARCAS, quien entiende que la Unión Europea comprende tanto a las Comunidades Europeas como a los Estados miembros. En este sentido vide LEAL-ARCAS, R. (2006), EU Legal Personality in Foreign Policy?, Paper 1754, Berkeley Electronic Press, http://law.bepress.com/expresso/eps/1754 (última consulta: diciembre 2009).

55 Así, MARQUARDT, S. (2001), «The conclusion of international agreements under article 24 of the Treaty on European Union", KRONENBERGER, V. (ed.), The European Union and the International Legal Order: Discord or Harmony?, T.M.C. Asser Press, The Hague, pp. 341-342. Efectivamente, la práctica así lo ha demostrado, y los acuerdos firmados por la UE con terceros países y con organizaciones internacionales se hacen en nombre de la Unión, y se rubrican por un representante de la Unión y el correspondiente del tercer Estado o de la organización internacional. Se publican en el Diario Oficial como anexos de la correspondiente Decisión PESC. Así, vide la Decisión 2001/352/PESC del Consejo, de 9 de abril de 2001, relativa a la celebración del Acuerdo entre la Unión Europea y la República Federativa de Yugoslavia (RFY) sobre las actividades de la Misión de Observación de la Unión Europea (MOUE) en la República Federativa de Yugoslavia, Diario Oficial de las Comunidades Europeas, L 125/53, de 5 mayo 2001 (en la versión en inglés puede verse, incluso, la rúbrica de los representantes). También, aunque ya con Niza, (en concreto, el Tratado de Niza entró en vigor el 1 de febrero de 2003), Decisión 2003/211/PESC del Consejo, de 24 de febrero de 2003, relativa a la celebración del Acuerdo entre la Unión Europea y la Organización del Tratado del Atlántico Norte sobre la seguridad de la información, Diario Oficial de la Unión Europea, L 80/35, de 27 marzo 2003. Más problemático, por su parte, resultaría afirmar otro tanto del que, en principio, parece la transposición del referenciado artículo al tercer pilar, es decir, el artículo 38 TUE. La razón de esta afirmación se encuentra en el contenido del artículo 29 TUE, que habla de la elaboración de una acción común en este campo «entre los Estados miembros». Vide FERNÁNDEZ SOLA, N. (2002), «La subjetividad internacional de la Unión Europea», op. cit., p. 100. 
Otro de los argumentos que emplean los partidarios de negar que esta capacidad convencional equivalga a reconocimiento implícito de la personalidad internacional de la UE se deriva del contenido del párrafo quinto del artículo 24 del TUE. Dicha disposición establecía:

«Ningún acuerdo será vinculante para un Estado miembro cuyo representante en el Consejo declare que tiene que ajustarse a las exigencias de su propio procedimiento constitucional; los restantes miembros del Consejo podrán acordar, no obstante, que el acuerdo se les aplique provisionalmente».

La lectura del segundo inciso del artículo 24.5 llevaría a concluir que con esta disposición el Tratado se refería a la aplicabilidad de un tal acuerdo en el interior de los Estados, no estrictamente a su obligatoriedad desde un punto de vista internacional. Así, para lograr su obligatoriedad interna en los distintos Estados miembros - que no en la Unión Europea, a quien obligaría desde su ratificación - habría que seguir trámites análogos a los seguidos cuando se pretende introducir en Derecho interno un Convenio adoptado por un órgano de una Organización internacional. Ese tratado no sería, pues, Derecho comunitario que, como tal, se inserta directamente en los ordenamientos jurídicos nacionales y vincula a la Comunidad y a sus Estados miembros, sino que sería Derecho internacional necesitado de seguir la tramitación constitucionalmente establecida en cada Estado ${ }^{56}$. De aceptar esta interpretación, el tratado sería inmediatamente vinculante para las instituciones de la Unión, aunque pudiera demorar su aplicación en algún Estado miembro.

Esta argumentación tendría su principal punto débil en la previsión de aplicación provisional del tratado adoptado conforme al artículo 24 TUE, ya que, como es bien sabido, esta institución tiene carácter previo a la entrada en vigor del tratado para los sujetos que lo han suscrito y persigue la correcta cumplimentación de los trámites internos requeridos para la prestación del consentimiento. Por lo tanto, no puede afirmarse jurídicamente que un tratado es internacionalmente obligatorio para la Unión y se aplica provisionalmente a sus Estados miembros si se considera que éstos no son parte del mismo sino que el

56 Ibidem. Otros autores, estiman que estos acuerdos obligan a la UE como tal. Una vez firmados y ratificados por la UE, cada Estado miembro tiene la obligación de abrir el procedimiento para poner de acuerdo su Constitución con dicho acuerdo si fuera necesario. Excepcionalmente un Estado podría formular la «reserva» de las exigencias de su ordenamiento constitucional (tal y como prevé el artículo $24 \mathrm{TUE}$ ) para no quedar vinculado, lo cual constituiría una figura única en el Derecho internacional, GRILLER, S., DROUTSAS, D. P., FALKNER, G., FORGÓ, K., NENTWICH, M. (2000), The Treaty of Amsterdam. Facts, Analysis, Prospects, Springer, Vienna/New York, pp. 387-390. 
sujeto contratante es la UE. Por ello, algún autor ha propuesto interpretar que ese Estado en cuestión argumenta una necesidad de Derecho interno de someterse a determinados trámites nacionales para manifestar su consentimiento en un órgano, el Consejo, que es quien debe suscribir el tratado en cuestión, por unanimidad. En apoyo de este razonamiento podría esgrimirse la frase que sigue inmediatamente a la analizada y según la cual, los restantes miembros del Consejo podrán decidir que el acuerdo se les aplique provisionalmente ${ }^{57}$. Por tanto, el acuerdo concluido sobre esta nueva base jurídica, se aplicará provisionalmente hasta que los trámites constitucionales del Estado que ha realizado la declaración se cumplimenten en sentido positivo y pueda votar afirmativamente en el Consejo y éste, en nombre de la Unión, manifestar su consentimiento en obligarse por el mismo ${ }^{58}$.

De manifestar su voto en contra, la doctrina opina que no podría ser objeto de prestación del consentimiento por la Unión, por falta de la unanimidad requerida por el artículo $24 \mathrm{TUE}^{59}$. De ser negativo el resultado del procedimiento constitucional nacional, el Estado afectado podría optar por la declaración cualificada de reconocer que, pese a no serle oponible, el acuerdo vincula a la Unión ${ }^{60}$. Con esta previsión, el TUE facilitaría una válvula de desbloqueo a la posible conclusión de un tratado por la UE aunque no concurra la voluntad de participación en el mismo de uno de sus miembros. Por tanto, la disposición comentada se situaría, no en el momento de prestación del consentimiento y posterior entrada en vigor del tratado, sino en el previo de la formación de la voluntad comunitaria con la posibilidad de aplicación provisional del tratado en

57 Esta institución —la aplicación provisional— está regulada por el artículo 25 del Convenio de Viena sobre Derecho de los tratados y el fin que persigue es poder dar efectividad a un tratado que requiere un número de ratificaciones determinado para su entrada en vigor o la cumplimentación de requisitos de Derecho interno de los sujetos negociadores que todavía no ha alcanzado (en este caso, la unanimidad de los Estados miembros de la UE).

58 FERNÁNDEZ SOLA, N. (2002), «La subjetividad internacional de la Unión Europea», op. cit., p. 102.

59 MARQUARDT, S. (2001), «The conclusion of international agreements under article 24 of the Treaty on European Union", op. cit., p. 346.

${ }^{60}$ Otros autores adoptan una postura algo más ambigua. Hay quien, aceptando de entrada la personalidad internacional implícita de la UE, sin embargo, respecto a esta cláusula de «escape» se limita a afirmar que la técnica a la que daría lugar el acuerdo sería parecida a la de un acuerdo mixto, puesto que para su entrada en vigor habría que esperar la ratificación de ese Estado miembro. Así, vide, STOFFEL VALLOTON, N., PÉREZ GONZÁLEZ, M. (1998), «La cuestión de la Naturaleza jurídica de la Unión Europea. El problema de la personalidad jurídica», OREJA AGUIRRE, M. (coord.), El Tratado de Ámsterdam: Análisis y Comentarios, Mac Graw Hill, Madrid, pp. 187-200, en concreto, p. 197. 
cuestión. Esta interpretación del artículo, que ya se planteó en estos términos con anterioridad al Tratado de Niza, quedaría definitivamente confirmada por la redacción que esa reforma dio a este precepto. Así, tras la nueva redacción desapareció el requisito permanente de la unanimidad del Consejo para la adopción de tales acuerdos y se afirmaba expresamente que los mismos vincularían a las instituciones de la Unión. La negativa en este caso de algún Estado miembro a votar favorablemente en el Consejo por impedimentos constitucionales sólo impediría la ratificación del acuerdo por la Unión si procediera del número de Estados suficiente para impedir la formación de la mayoría requerida ${ }^{61}$.

20. Por otra parte, en la Convención sobre el futuro de la Unión que preparó el malogrado «Tratado por el que se instituye una Constitución para Europa» se formó rápidamente un amplio consenso sobre la necesidad de reconocer a la UE personalidad jurídica, e incluso, de fusionar las Comunidades subsistentes en una sola organización, la Unión, aunque, finalmente, se mantuviese la personalidad de la Comunidad Europea de la Energía Atómica (EURATOM $)^{62}$. El resultado fue el artículo I-7 del Tratado Constitucional, que aseveraba sin rodeos: «La Unión tiene personalidad jurídica»" ${ }^{63}$. Y es que, tal y como sostiene una autorizada voz, habiendo sido aceptada en el terreno de los hechos, el reconocimiento en los Tratados de la personalidad jurídica de la Unión era un hecho inevitable en la siguiente reforma de los Tratados ${ }^{64}$.

${ }^{61}$ Algún eminente autor ha querido ver en este sistema del artículo 24 «una analogía con la llamada cláusula federal, por medio de la cual el gobierno federal, cuando concluye un tratado, estipula que el tratado sólo obligará a los gobiernos de los estados miembros en sus estados si éstos, posteriormente, así lo aprueban; lo cual no implica que los gobiernos de los estados miembros sean parte del tratado internacional», DE WITTE, B. (1998), «The pillar structure and the nature of the European Union: Greek temple or French Gothic cathedral?», op. cit., pp. 63-64. Del mismo parecer, DEHOUSSE, R. (1991), Fédéralisme et relations internationales, Bruylant, Bruxelles, pp. 182-189.

62 Vide el artículo IV-437, «Derogación de los Tratados anteriores», el artículo IV-438, «Sucesión y continuidad jurídica» y el Protocolo núm. 36, por el que se modifica el Tratado constitutivo de la Comunidad Europea de la Energía Atómica. Sobre esta cuestión, vide FASSBENDER, B. (2004), «Die Völkerrechtssubjektivität der Europäischen Union nach dem Entwurf des Verfassungsvertrages», Archiv des Völkerrechts, Vol. 42, pp. 26-43, cuyas conclusiones seguirían siendo válidas en caso de que el Tratado de Lisboa fuera finalmente ratificado.

${ }^{63}$ De hecho, uno de los grupos de trabajo de la Convención, concretamente el III, presidido por Giuliano AMATO, vicepresidente, además, de la Convención, se dedicó exclusivamente al tema de la personalidad jurídica de la Unión. Las conclusiones de dicho grupo pueden consultarse en el documento Informe final del Grupo III «Personalidad Jurídica», CONV 305/02, presentado a la Convención el 1 de octubre de 2002.

${ }^{64}$ JACQUE, J. P. (2006), Droit institutionnel de l'Union européenne, op. cit., p. 166. 


\subsection{Práctica convencional y diplomática.}

21. La práctica convencional de la Unión ha venido a confirmar la interpretación que se viene defendiendo y según la cual el artículo 24, definitivamente, demuestra la personalidad internacional de la Unión Europea ${ }^{65}$. En este sentido, la acción conjunta aprobada por el Consejo el 22 de diciembre de 2000 que reestructuraba la Misión de control en los Balcanes occidentales (EUMM) remitía a un acuerdo concluido con base en el artículo 24 TUE para establecer las normas detalladas aplicables a las operaciones de la Misión. Este mandato se materializaba el 20 de marzo de 2001 mediante la conclusión del acuerdo entre la UE y la República federal de Yugoslavia sobre las actividades de la Misión de control de la UE en este país donde queda claro que se concluye por la Presidencia en nombre de la $\mathrm{UE}^{66}$.

En el mismo sentido se concluyó el acuerdo entre la UE y la ex República yugoslava de Macedonia. La decisión del Consejo relativa a la celebración de dicho acuerdo tiene también su base en el artículo 24 TUE y, en su artículo primero, se explicita que el mismo se aprueba en nombre de la Unión Europea ${ }^{67}$.

Respecto a los efectos de tales acuerdos concluidos sobre la base del artículo 24 TUE, es posible afirmar su obligatoriedad para las instituciones de la Unión y para los Estados miembros, salvo para aquél o aquéllos que hayan realizado la declaración antes comentada. Precisamente esta posibilidad de quedar al margen de la aplicación de un tratado concluido por la UE es prueba manifiesta, como se dejó entrever, del carácter vinculante para los demás. Si a este reconocimien-

${ }^{65}$ No obstante, mostrando algunas reticencias, vide GAUTRON, J. C. (2007), «Article I-7 - Personnalité juridique», BURGORGUE-LARSEN, L., LEVADE, A., PICOD, F. (coords.), Traité établissant une Constitution pour l'Europe: commentaire article par article, Bruylant, Bruxelles, Vol. 1, pp. 117-122, especialmemte, pp. 118-120.

66 Vide Acción común 2000/811/PESC, de 22 de diciembre de 2000, relativa a la Misión de Observación de la Unión Europea, que transforma la MOCE en MOUE, como instrumento de la Política Exterior y de Seguridad Común (PESC) de la Unión Europea, sobre la base de iniciativas anteriores, para contribuir a la elaboración efectiva de la política de la Unión Europea para los Balcanes Occidentales, Diario Oficial de las Comunidades Europeas, núm. L 328/53, de 23 diciembre 2000; Decisión del Consejo 2001/352/PESC, de 9 de abril de 2001, relativa a la celebración del Acuerdo entre la Unión Europea y la República Federativa de Yugoslavia, y el correspondiente Acuerdo, Diario Oficial de las Comunidades Europeas, núm. L 125/1, de 5 mayo 2001.

${ }^{67}$ Vide Decisión del Consejo 2001/682/PESC, de 30 de agosto de 2001, relativa a la celebración del Acuerdo entre la Unión Europea y la ex República Yugoslava de Macedonia (ERYM) sobre las actividades de la Misión de Observación de la Unión Europea (MOUE) en la ERYM, y el correspondiente Acuerdo, Diario Oficial de las Comunidades Europeas, núm. L 241/1, de 11 septiembre 2001. 
to implícito en los Tratados de la capacidad convencional de la Unión se añade el reconocimiento en la práctica de su derecho de legación pasivo y la determinación de la representación internacional de la Unión a través de la Presidencia, del Alto Representante para la política exterior y de seguridad común y de los enviados especiales (Oriente Medio, Grandes Lagos, Kosovo, etc.), se tienen presentes los principales elementos integradores de la personalidad internacional ${ }^{68}$. Sin embargo, cabría preguntarse si a la anterior afirmación se opone la Declaración núm. 4 aneja al Tratado de Ámsterdam. Dicha disposición establecía:

«Las disposiciones de los artículos 24 y 38 del Tratado de la Unión Europea y cualquier acuerdo resultante de las mismas no llevarán implícito ningún traspaso de competencias de los Estados miembros a la Unión Europea».

En primer lugar, desde un punto de vista formalista, se podría replicar que esta Declaración se refiere a las competencias y no a la personalidad de los sujetos de Derecho. Además, con la pretensión de excluir explícitamente la transferencia de competencias a la Unión, se estaría confirmando implícitamente que existe un sujeto a favor del cual se podría operar dicha transferencia ${ }^{69}$. Por otra parte, desde un punto de vista internacionalista, la UE actuaría en un ámbito intergubernamental en el que, por definición, no se produce transferencia de competencias soberanas a la Organización. Además, tampoco se produce dicho traspaso, por ejemplo, a la ONU ni a otras Organizaciones por parte de sus Estados, lo cual no impide reconocer su subjetividad internacional ${ }^{70}$. Por otra parte, más bien parece que la mencionada declaración expresa, sobre todo, la preocupación de los Estados miembros de evitar las consecuencias de la célebre jurisprudencia $A E T R^{71}$.

${ }^{68}$ Algunos países, como Estados Unidos, han procedido, como los Estados miembros, al cambio de la denominación de la Oficina de representación diplomática, que pasa a ser representación ante la Unión Europea, en vez de ante la Comunidad Europea.

${ }^{69}$ En el mismo sentido, vide TIZZANO, A. (1999), "La personnalité internationale de l'Union Européenne», op. cit., p. 189.

${ }^{70}$ FERNÁNDEZ SOLA, N. (2002), «La subjetividad internacional de la Unión Europea», op. cit., p. 107.

${ }^{71}$ Este temor por parte de los Estados se viene manifestando desde la citada jurisprudencia y tuvo una de sus primeras manifestaciones en la una de las Declaraciones anexas al Acta final del Tratado de Maastricht, en concreto, la Declaración (núm. 10) relativa a los artículos 111 (antiguo artículo 109), 174 (antiguo artículo $130 \mathrm{R}$ ) y 181 (antiguo artículo $130 \mathrm{Y}$ ) del Tratado constitutivo de la Comunidad Europea, que decía lo siguiente: «La Conferencia considera que las disposiciones del apartado 5 del artículo 111, del segundo párrafo del apartado 4 del artículo 174 y del artículo 181 no afectan a los principios que se derivan de la sentencia del Tribunal de Justicia en el caso AETR». 
22. La última cuestión que se intentará esclarecer en el propósito de determinar la atribución implícita de personalidad jurídica internacional a la UE sería la de su legitimación como sujeto de reclamaciones internacionales y su capacidad como sujeto activo y pasivo de responsabilidad internacional. Siguiendo la lógica del razonamiento anterior, la contestación a estas cuestiones habría de ser positiva. En principio, nada se opondría a ello, pues la UE tiene órganos para actuar y medios financieros para hacer frente a sus eventuales responsabilidades ${ }^{72}$. Por otra parte, en el plano interno, cuando el Tribunal de Justicia estima una demanda, reconoce la responsabilidad de una u otra institución, no de la Comunidad (ni tampoco de la Unión) como un todo ${ }^{73}$. De todos modos, se hace necesario que la práctica dote de contenido real a esta posible personalidad internacional; es decir, que existan unas competencias reales para actuar internacionalmente, aceptadas unánimemente por los Estados miembros. Si la Unión concluye acuerdos internacionales del tipo previsto en el artículo 24, respecto a ellos, a su aplicación y contenido, podrá responder internacionalmente y tendrá legitimación ante organismos internacionales. Otra cosa distinta serían los modos de hacer efectiva esa responsabilidad (en el caso de una hipotética responsabilidad pasiva). En la situación tras el Tratado de Niza, además, se haría necesario que dicha responsabilidad tuviera un carácter solidario con la de los Estados miembros pues, sin el necesario concurso de todos ellos, la UE no puede acordar tales compromisos internacionales. En cualquier caso, siempre se podría argumentar que ésta es una cuestión interna a ventilar entre la UE y sus Estados miembros quienes, en su caso, deberían dar cumplida satisfacción a las exigencias de Estados terceros u Organizaciones internacionales ${ }^{74}$.

23. En la práctica internacional, junto a algunas realizaciones concretas, la UE es percibida, tanto por la opinión pública como por los medios de comunicación y por los terceros Estados con los que mantiene relaciones, como una

72 Ya desde Maastricht, el presupuesto se denomina «Presupuesto de la Unión Europea». Actualmente, los artículos 28 y 41 del TUE establecen el presupuesto único, al que se imputarán todos los gastos derivados de la actividad de las Comunidades y de la UE.

73 Asuntos acumulados C-104/89 y C-37/90, Mulder y otros vs. Consejo, Sentencia del TJCE de 19 mayo 1992, Recopilación de Jurisprudencia, 1992, p. I-03061, \$9 y \$24-25. Lo mismo sucede en el caso de demandas contractuales. En este sentido, vide el asunto C-42/94, Heidemij Advies vs. Parlamento, Sentencia del TJCE de 1 junio 1995, Recopilación de Jurisprudencia, 1995, p. I-01417, $\$ \$ 13-21$.

74 También comparte estas tesis, entre otros, FERNÁNDEZ SOLA, N. (2002), «La subjetividad internacional de la Unión Europea», op. cit., p. 108. 
entidad política y la mayoría de los comentaristas están a favor del reconocimiento de su personalidad jurídica ${ }^{75}$.

No obstante, la ausencia de una personalidad jurídica expresa ha planteado problemas, tal y como se vio en el caso de la participación de la Unión en la "Comisión de Consolidación de la Paz» de las Naciones Unidas. La Comisión de Consolidación de la Paz fue creada en las resoluciones A/RES/60/180 y S/RES/1645(2005), de 20 de diciembre de 2005, por la Asamblea General y el Consejo de Seguridad de las Naciones Unidas, respectivamente, con un mandato que pretende, en términos generales, financiar, asesorar y canalizar recursos y para asesorar y proponer estrategias integrales de consolidación de la paz y recuperación después de los conflictos ${ }^{76}$. Después de unas complejas negociaciones a tres bandas, Comisión, Consejo y Naciones Unidas, con dictámenes jurídicos de por medio, se acordó conceder dos asientos a la delegación comunitaria pero bajo la pancarta «Comunidad Europea» y no "Unión Europea». Cada uno de los asientos estará ocupado por un miembro de la Comisión y otro del Consejo, lo que sin duda está llamado a producir ciertas fricciones (el Consejo ostenta la alta representación internacional, pero la Comisión paga) hasta que se haga efectiva la figura del Alto Representante establecida en el Tratado de Lisboa, según el cual esa figura es, a la vez, vicepresidente de la Comisión y responsable de los asuntos exteriores en el Consejo ${ }^{77}$.

\section{LA UNIÓN EUROPEA COMO UNA ÚNICA ORGANIZACIÓN}

24. La principal tesis que se pretende haber demostrado mediante la defensa de la existencia de personalidad jurídica de la UE antes de su reconocimiento expreso es la de que se está ante un solo sujeto. Es decir, no se tiene a las Comu-

75 En este sentido, vide el informe de la Presidencia irlandesa al Consejo europeo de Dublín (diciembre de 1996) titulado Adaptar la Unión Europea en beneficio de sus pueblos y prepararla para el futuro. Líneas generales de un proyecto de revisión de los Tratados, presentado el 5 de diciembre de 1996, CONF 2500/96. En concreto, el Capítulo III de dicho documento está dedicado a la «Personalidad Jurídica de la Unión», pp. 87-89.

${ }^{76}$ Sobre este nuevo órgano de las Naciones Unidas, vide THALLINGER, G. (2007), «The UN Peacebuilding Commission and Transitional Justice», German Law Journal, Vol. 8/7, pp. 681-710.

77 Sobre esta cuestión vide HAMONIC, A. (2008), «La représentation de l'Union Européenne au sein de la Commission de consolidation de la paix des Nations Unies: entre anticipation et continuité», Cahiers de Droit Européen, Vol. 44/5-6, pp. 591-627, especialmente, 625-627. En la propia documentación interna del órgano de la ONU se afirmaba que esta solución híbrida es «temporal», hasta que el Tratado de Lisboa entrase en vigor. Ibídem, p. 620. 
nidades por un lado y a la Unión Europea por otro (sea otra organización o un mero calificativo de la cooperación intergubernamental), sino que se está ante una misma organización ${ }^{78}$.

Por otro lado, aunque el análisis de la personalidad jurídica de una organización es relevante, en el caso de la Unión no debería ser el elemento crucial en el análisis jurídico del entramado comunitario ${ }^{79}$. Ciertamente, en Derecho internacional público, la mayoría de los autores considera la personalidad jurídica internacional vital porque normalmente constituye la conditio sine qua non de la capacidad de actuar de una organización internacional. Esta capacidad de actuar está limitada, en la mayoría de los casos, al plano internacional. Así, como se ha señalado, faculta a los órganos de la organización para relacionarse e interactuar con otros sujetos de Derecho internacional, permite personarse ante los tribunales internacionales y permite, eventualmente, determinar la responsabilidad de la organización ${ }^{80}$. No parece pues, apropiado, aprehender la naturaleza jurídica (o la estructura jurídica organizacional) exclusivamente desde el estudio de su personalidad jurídica internacional, dado que la capacidad de la UE de relacionarse con otros sujetos de Derecho internacional es sólo un aspecto de su entramado competencial. Es posible encontrar, por ejemplo, una competencia interna de la UE en el artículo 7 TUE (referente a la violación reiterada, por un Estado, de los Derechos fundamentales) o en el artículo 34 TUE, en relación con el 32 (referentes a la cooperación policial y judicial en materia penal) ${ }^{81}$.

25. El hecho de que, dentro de la Unión, convivan diferentes instituciones y organismos dotados todos ellos de personalidad jurídica no es óbice para reconocer la subjetividad de la Unión Europea, como ente aglutinador de todos

78 Esta es la opinión de los autores que defienden la tesis de la unidad (con VON BOGDANDY y DE WITTE a la cabeza). Así, vide VON BOGDANDY, A. (1999), «The legal case for unity: the European Union as a single organization with a single legal system», Common Market Law Review, Vol. 36/5, pp. 887-910, en concreto, vide, p. 891. Algún otro autor, ha llegado a formular explícitamente, sin embargo, la teoría de que son organizaciones diferenciadas, OPPERMANN, T. (1999), Europarecht: ein Studienbuch, Beck, München, Vol. 2, p. 75, nota 154.

79 VON BOGDANDY, A. (1999), «The legal case for unity: the European Union as a single organization with a single legal system», op. cit., p. 893.

${ }^{80}$ No obstante, incluso en Derecho internacional, los conceptos de personalidad jurídica y de personalidad jurídica internacional pueden separarse, tal y como se desprende del análisis efectuado del caso Bernadotte (vide supra).

${ }^{81}$ Así piensa, entre otros, VON BOGDANDY, A. (1999), «The legal case for unity: the European Union as a single organization with a single legal system», op. cit., p. 893. 
ellos $^{82}$. El siguiente paso dado, el reconocimiento explícito de una personalidad jurídica propia revestiría connotaciones de más marcado carácter político que jurídico, ya que, como se ha visto, ad extra ya se le reconoce personalidad propia a la UE, sólo ad intra algunos Estados muy celosos de su soberanía (Reino Unido) o de su identidad nacional (desde Francia hasta Dinamarca), o una Comisión que se ve debilitada, han puesto históricamente pegas al reconocimiento interno de la misma; lo que, por otra parte, tampoco reviste mayores problemas prácticos, ya que se ha empleado auxiliarmente la de las Comunidades. Es por ello que se ha extendido la práctica de hablar de la UE/CE (o CE/UE) para obviar la discusión sobre la personalidad jurídica de la Unión Europea, contribuyendo así a apuntalar la tesis de la existencia de una única organización ${ }^{83}$.

El malogrado Tratado Constitucional, primero, y el Tratado de Lisboa, después, han tratado de clarificar esta situación, especialmente, de cara al exterior, confiriendo personalidad jurídica expresa a la Unión Europea (artículo 47 TUE-L) que, además, sucederá a la Comunidad Europea (artículo 1, párrafo 3 TUE, tras Lisboa). La Comunidad Europea de la Energía Atómica (EURATOM), sin embargo, continuaría existiendo como entidad jurídica separada con personalidad jurídica propia.

26. El Tratado de Lisboa recupera el consenso al que se llegó en la redacción del Tratado Constitucional sobre la necesidad de que la Unión Europea cuente con una personalidad jurídica, expresa y única. En efecto, el artículo 47 del Tratado de la Unión, según la redacción que le ha dado Lisboa, dispone:

«La Unión tiene personalidad jurídica».

${ }^{82}$ DE WITTE, B. (1998), «The pillar structure and the nature of the European Union: Greek temple or French Gothic cathedral?», op. cit., pp. 58-59. Nótese que no sólo las Comunidades tienen reconocida personalidad jurídica, también la tienen reconocida el Banco Central Europeo y el Banco Europeo de Inversiones. Por ello, parece más adecuada la tesis del profesor belga que considerar a las Comunidades como sub-organizaciones también dotadas de personalidad jurídica, que las tesis iniciales de VON BOGDANDY, que consideraba que las Comunidades no tenían existencia legal tras Maastricht, sino que constituían solamente un régimen legal separado, en VON BOGDANDY, A., NETTESHEIM, M. (1996), «Ex Pluribus Unum: (...)», op. cit., p. 275. También consideran a las Comunidades como subsistemas dentro de la UE, CURTIN, D. M., DEKKER, I. F., «The EU as a "Layered» International Organization: Institutional Unity in Disguise», CRAIG, P., DE BÚRCA, G., The Evolution of EU Law, OUP, Oxford, 1999, pp. 87 y 104-131.

83 Vide, inter alia, CRAIG, P., DE BÚRCA, G. (2998), EU Law. Text, Cases and Materials, 4th ed., op. cit., p. 384, cuando analiza la posibilidad de que la CE/UE esté vinculada por el Convenio Europeo de Derechos Humanos. 
Así pues, el Tratado de Lisboa extingue la Comunidad Europea, cuya sucesión asume la propia Unión Europea. En este sentido, el último inciso el último párrafo del artículo 1 del TUE, reformado por Lisboa, establece:

«La Unión sustituirá y sucederá a la Comunidad Europea» ${ }^{84}$.

De esta forma, se consolidan en una Unión Europea con personalidad jurídica internacional las competencias y funciones que antes ejercían la UE y la CE. Se zanja finalmente la polémica y se abren importantes perspectivas en lo relativo a la representación de la Unión ante organizaciones internacionales, ya que le permitirá adherirse como tal a otras organizaciones internacionales y reforzará la percepción que de ella se tienen en la escena internacional ${ }^{85}$.

Desde el punto de vista de la formulación de la política exterior europea, la decisión sobre la personalidad jurídica de la Unión Europea tiene como consecuencia la superación, al menos formalmente, de la estructura en pilares, lo que redundaría en una mayor unidad y coherencia de dicha política. Sin embargo, la desaparición de los pilares no significa que todos los ámbitos de la política exterior vayan a ser sometidos a los mismos procedimientos de toma de decisiones y a un mismo modelo de gestión sino que se mantendrán procedimientos diferenciados ${ }^{86}$.

${ }^{84}$ Como consecuencia de esto, el Tratado de la Comunidad Europea pasaría a llamarse Tratado de Funcionamiento de la Unión Europea. El propio Tratado de Lisboa dispone que no hay relación jerárquica entre ellos, sino que «ambos Tratados tienen el mismo valor jurídico» (artículo 1, párrafo $3^{\circ}$ del TUE).

85 En este sentido, vide ALDECOA LUZÁRRAGA, F. (2008), «La política exterior común en el Tratado de Lisboa: instrumentos para hacer de la Unión un actor de la globalización», FERNÁNDEZ LIESA, C. R., DÍAZ BARADO, C. M. (coords.), El Tratado de Lisboa. Análisis y perspectivas, Instituto Universitario de Estudios Internacionales y Europeos «Francisco de Vitoria», Dykinson, Madrid, pp. 231-254.

${ }^{86}$ Algunos autores sostienen que, a pesar de la unificación operada en la Unión por el Tratado Constitucional, primero, y el Tratado de Lisboa que sigue en lo esencial al anterior, después, se mantiene la clásica estructura en pilares se mantiene internamente a pesar de las apariencias externas. Sobre el caso del fallido Tratado Constitucional vide, WESSELS, W. (2004), "A 'saut constitutionnel' out of an intergovernmental trap? The Provisions of the Constitutional Treaty for the Common Foreign, Security and Defence Policy», WEILER, J. H. H., EISGRUBER, C. L. (eds.), Altneuland: The EU Constitution in a Contextual Perspective, Jean Monnet Working Paper 5/04, New York / Princeton, disponible en el siguiente enlace <http://www.jeanmonnetprogram.org/papers/04/040501-17.html>, última consulta: mayo 2009, especialmente, p. 10. Sobre el Tratado de Lisboa, vide GONZÁLEZ ALONSO, L. N. (2008), «¿Quién dijo que desaparecen los pilares? La configuración jurídica de la acción exterior de la Unión Europea en el Tratado de Lisboa», MARTÍN Y PÉREZ DE NANCLARES, J. (coord.), El Tratado de Lisboa : la salida de la crisis constitucional, Iustel, Madrid, pp. 393-403. 
En cualquier caso, la sustitución va a suponer la necesidad, ya constatada por el Consejo, de notificar a los terceros Estados con los que las Comunidades y/o la Unión tienen acuerdos en vigor así como a las organizaciones en las que participen ese hecho, a los efectos de proceder a la sucesión ${ }^{87}$.

27. Uno de los problemas que la situación anterior provocaba y que podría quedar resuelto tras la reforma operada por el Tratado de Lisboa es el de la posibilidad de celebrar acuerdos internacionales cuyo contenido afecte a tradicionales políticas comunitarias, como podría ser la comercial, y a cuestiones de política exterior en sentido más político. Esta cuestión fue abordada por el Tribunal de Justicia con anterioridad a la entrada en vigor de Lisboa, reafirmando su papel como tribunal constitucional más allá del ámbito estrictamente comunitario ${ }^{88}$.

En este sentido, el TJCE decidió que podía haber situaciones en las que la Comunidad invadiese competencias propias de la Unión en los otros pilares. Así, en el caso $P N R$, el Tribunal de Luxemburgo estableció que el acuerdo entre la Unión Europea y los Estados Unidos sobre tratamiento de datos de los pasajeros no debía haberse basado en el artículo 95 TCE (sobre el mercado interior), sino que implícitamente, el Tribunal apuntó al tercer pilar para hallar la base jurídica adecuada, concretamente al artículo 38 del TUE ${ }^{89}$. Así, parecería que para determinar el «centro de gravedad» de un instrumento comunitario, el TJCE no se circunscribió exclusivamente a las bases jurídicas que ofrecía el Tratado de la Co-

87 Así aparece recogido en la Nota de la Presidencia 14784/09 de 22 de octubre sobre la situación de los trabajos relativos a la notificación referente al artículo 1, párrafo tercero, del Tratado de la Unión Europea, en la versión que se derivaría de las modificaciones introducidas por el Tratado de Lisboa, en la que se recogen los modelos de notificación tanto a los Estados terceros como a las organizaciones internacionales.

${ }^{88}$ Y esto a pesar de que el papel del TJCE en la PESC es prácticamente nulo y de que el Tratado de Lisboa haya mantenido esta situación. Una importante excepción sería la recogida en el artículo 275 del Tratado de Funcionamiento de la Unión Europea sobre la posibilidad de efectuar un cierto control de la legalidad de las sanciones internacionales sobre personas físicas o jurídicas. Sobre esta cuestión, vide WESSEL, R. A. (2009), «The Dynamics of the European Union Legal Order: An Increasingly Coherent Framework of Action and Interpretation», European Constitutional Law Review, Vol. 5/1, pp. 117-142, especialmente, p. 134.

${ }^{89}$ Asuntos acumulados C-317/04 y C-318/04, Parlamento vs. Consejo, Sentencia del TJCE de 30 de mayo de 2006, Recopilación de jurisprudencia, 2006, p. I-4721, conocido como caso PNR («Passenger Name Record»), especialmente, \$\$54-61 y 67-70. Sobre este caso, vide GILMORE, G., RIJPMA, J. (2007), "Joined Cases C-317/04 and C-318/04, European Parliament v. Council and Commission, Judgment of the Grand Chamber of 30 May 2006, [2006] ECR I-4721», Common Market Law Review, Vol. 44/4, pp. 1081-1099. Igualmente, vide MENDEZ, M. (2007), "Passenger Name Record Agreement - European Court of Justice», European Constitutional Law Review, Vol. 3/1, pp. 127-147. 
munidad Europea, sino que fue más allá, integrando el Tratado de la Unión en sus consideraciones ${ }^{90}$.

Este argumento ya fue confirmado en relación con la PESC en el caso $C E$ $D A O$ (más conocido como "ECOWAS», por sus siglas en inglés) ${ }^{91}$. En este asunto la Comisión interpuso una demanda en la que solicitaba al TJCE que anulara dos decisiones adoptadas por el Consejo en el marco de la PESC: la Acción Común 2002/589/PESC y Acción Común 2002/589/PESC y la Decisión 2004/833/PESC, de aplicación de la anterior, en el marco de la contribución de la Unión Europea para combatir la acumulación desestabilizadora y la proliferación de armas ligeras y de pequeño calibre ${ }^{92}$. El caso ECOWAS concedió al TJCE una oportunidad para concretar su interpretación del artículo 47 del TUE en un caso que afectaba al primer y segundo pilar. El Abogado General, Sr. MENGOZZI, argumentó que:

«[el] nexo entre el mantenimiento de la paz y el fortalecimiento de la seguridad internacional (...) y la prevención de los conflictos, por una parte, y el desarrollo, por otra (...) no puede abocar a incluir en el campo de la cooperación al desarrollo medidas que lleven a vulnerar el reparto de competencias en el marco de la arquitectura de pilares de la Unión Europea»`3.

En su opinión, «la finalidad perseguida por el Decisión impugnada [combatir la proliferación de armas ligeras], a la luz de la Acción Común controvertida, estaba orientada a la seguridad pública, al menos principalmente» con lo que encontraba su fundamento en la PESC ${ }^{94}$.

${ }^{90}$ En este sentido, vide WESSEL, R. A. (2009), «The Dynamics of the European Union Legal Order: An Increasingly Coherent Framework of Action and Interpretation», op. cit., p. 135.

${ }^{91}$ Asunto C-91/05, Comisión vs. Consejo, Sentencia del TJCE de 20 mayo 2008, Recopilación de jurisprudencia, 2008, p. I-3651, conocido como caso CEDAO («Comunidad Económica de los Estados del Africa del Oeste») o, por sus siglas en inglés, ECOWAS («Economic Community Of West African States). Para un comentario, vide HELISKOSKI, J. (2008), «Small arms and light weapons within the Union's pillar structure: An analysis of Article 47 of the EU Treaty», European Law Review, Vol. 33/6, pp. 898-912.

92 Vide la Decisión 2004/833/PESC del Consejo, de 2 de diciembre de 2004, por la que se aplica la Acción Común 2002/589/PESC con vistas a una contribución de la Unión Europea a la CEDEAO en el marco de la moratoria sobre las armas ligeras y de pequeño calibre, Diario Oficial de la Unión Europea, núm. L 359/65, de 4 diciembre 2004 y la Acción Común 2002/589/PESC del Consejo, de 12 de julio de 2002, sobre la contribución de la Unión Europea para combatir la acumulación desestabilizadora y la proliferación de armas ligeras y de pequeño calibre, y por la que se deroga la Acción común 1999/34/PESC, Diario Oficial de la Unión Europea, núm. L 191/1, de 19 julio 2002.

93 Conclusiones del Abogado General, Sr. MENGOZZI, en el asunto C-91/05, Comisión vs. Consejo, Sentencia del TJCE de 20 mayo 2008, caso ECOWAS, op. cit., \$169-170.

${ }^{94}$ Ibidem, $\$ 212$. 
El TJCE no llegaría a la misma conclusión y la sentencia de la Gran Sala estableció que:

«[Un acto generador de efectos jurídicos adoptado en el marco del título $\mathrm{V}$ del Tratado UE afecta a las disposiciones del Tratado CE en el sentido del artículo 47 UE siempre que hubiera podido adoptarse basándose en este último Tratado, sin que sea necesario examinar si dicho acto impide o limita el ejercicio de las competencias de la Comunidad (...).

[En este caso] la Decisión impugnada consta, atendiendo a su finalidad y su contenido, de dos componentes, sin que ninguno de ellos pueda considerarse accesorio del otro, pertenecientes, uno, al ámbito de la política comunitaria de cooperación al desarrollo y, el otro, al de la PESC»' ${ }^{95}$.

Por ello, a juicio del TJCE, la Acción Común debería de haberse implementado «tanto por la Unión, en el marco del título V del Tratado UE, como por la Comunidad, en el marco de su política de cooperación al desarrollo» ${ }^{96}$.

Lo importante de este caso es que el TJCE se centró en la interrelación entre instrumentos jurídicos que pertenecen a distintos pilares e incluso en la posible necesidad de implementar instrumentos de la PESC a través de actos comunitarios $^{97}$. La solución dependió del análisis de los hechos, es decir, de si éstos se incardinaban en la cooperación al desarrollo (primer pilar) o en la PESC (segundo), lo que llevó al TJCE a operar una división de competencias sobre la base del Derecho de la Unión Europea, en sentido estricto (el TUE). El Tribunal de Justicia solamente pudo llegar a establecer una solución tras tener en cuenta las medidas propias del segundo pilar. Ahora bien, esto no quiere decir que el caso ECOWAS haya abierto la puerta a una jurisdicción general del TJCE en el ámbito de la $\mathrm{PESC}^{98}$. Como se ha visto supra en los casos de sanciones contra individuos en el marco de la lucha contra el terrorismo, el juez comunitario no disponía de una base jurídica para anular Posiciones Comunes adoptadas en el

95 Asunto C-91/05, Comisión vs. Consejo, Sentencia del TJCE de 20 mayo 2008, caso ECOWAS, op. cit., $\$ \$ 60$ y 108.

96 Ibidem, $\$ 88$.

${ }^{97}$ En este sentido, vide HILLION, C., WESSEL, R. A. (2009), «Competence distribution in EU external relations after Ecowas: Clarification or continued fuzziness?», Common Market Law Review, Vol. 46/2, pp. 551-586, especialmente, pp. 574-578.

${ }^{98}$ GARBAGNATI KETVEL, M. G. (2006), «The Jurisdiction of the European Court of Justice in Respect of the Common Foreign and Security Policy", International \& Comparative Law Quarterly, Vol. 55/1, pp. 77-120, especialmente, p. 90. 
ámbito de la PESC, más allá del artículo 47 TUE ${ }^{99}$. De este modo, el juez comunitario avaló:

«[L]a coexistencia de la Unión y de la Comunidad como ordenamientos jurídicos integrados pero distintos y la arquitectura constitucional de los pilares» ${ }^{100}$.

La situación, obviamente cambiará con la entrada en vigor de la última reforma, si bien esto no hará desaparecer todos los problemas, al permanecer la política exterior como un ámbito al margen de los mecanismos ordinarios de funcionamiento.

28. Una última novedad, llamada a asentar a la Unión Europea en el mundo de las organizaciones internacionales es el llamado Servicio Europeo de Acción Exterior. Esta nueva «diplomacia» de la Unión Europea, que aparece recogida en el artículo 27.3 del TUE-L, al frente de la cual estará la Alto Representante para Asuntos Exteriores y Política de Seguridad, tiene una regulación extremadamente débil. Lo único que se regula es que colaborará con los servicios diplomáticos de los Estados miembros y que estará compuesta por «por funcionarios de los servicios competentes de la Secretaría General del Consejo y de la Comisión y por personal en comisión de servicios de los servicios diplomáticos nacionales» (al menos un tercio del total para este último grupo). Quedan por lo tanto por definir cuestiones tan esenciales como puede ser la de la delimitación precisa de sus funciones o la de su responsabilidad. En relación con la primera, la Presidencia elaboró una nota en octubre de 2009 para el Consejo Europeo en la que se presenta el trabajo llevado a cabo entre ella misma, los Estados miembros, la Comisión y la Secretaría del Consejo ${ }^{101}$. En la misma, se excluyen de sus competencias ampliación de la Unión así como la política comercial y la política de ayuda al desarrollo, que permanecerán en manos de la Comisión. Por el contrario, absorberá las delegaciones exteriores de la Comisión Europea, que pasarán a serlo de la Unión, así como las estructuras existentes en el Consejo de

99 Recuérdese que en los casos Sison y Al-Aqsa, el TPI anuló los Reglamentos comunitarios, pero no la Posición Común en la que éstos se basaban. Vide los asuntos T-47/03, Jose María Sison vs. Consejo, op. cit. y T-327/03, Stichting Al-Aqsa vs. Consejo, op. cit., todos ellos comentados supra.

100 Asuntos T-306/01, Yusufy Al Barakaat International Foundation vs. Consejo y Comisión, Sentencia del TPI de 21 septiembre 2005, op. cit. \$156 y T-315/01, Kadi vs. Consejo y Comisión, Sentencia del TPI de 21 septiembre 2005, op. cit., $\$ 120$.

101 Nota 14930/09, Informe de la Presidencia al Consejo Europeo sobre el Servicio Europeo de Acción Exterior. 
gestión de crisis. Parece delinearse un servicio que gozaría de un alto nivel de independencia, lo cual podría aumentar de manera significativa la efectividad de la personalidad jurídica de la Unión (al tiempo que podría provocar la reacción en contra de los Estados miembros con fuertes diplomacias tradicionales).

\title{
Title
}

THE NEW EUROPEAN UNION: FROM DUAL PERSONALITY TO PERSONALITY DISORDERS.

\section{Resumen}

La cuestión relativa a la personalidad jurídica de la Unión Europea ha sido una cuestión muy debatida por la doctrina. Hasta la entrada en vigor del Tratado de Lisboa, los textos convencionales no otorgaban expresamente personalidad a la UE aunque sí se la reconocían a las Comunidades. La dualidad CE/UE responde a las dos almas del proyecto de integración europeo (la vía comunitaria y la intergubernamental) y ha planteado no pocos problemas de funcionamiento ad extra (representación internacional de la CE y de la UE) y ad intra (la estricta división en pilares se ha topado con una compleja casuística que cuestiona dicha separación radical). Aunque la última reforma sustituye la estructura anterior otorgando personalidad jurídica expresa a la nueva Unión Europea, no por ello desaparecen todas las contradicciones heredadas del sistema precedente: se mantiene la Comunidad Europea de la Energía Atómica, parece subsistir una "pilarización» de facto o la débil regulación de la representación internacional que pretende ser única, entre otras cuestiones. En el presente trabajo se analizan estas cuestiones, desde la coexistencia del binomio CE/UE («doble personalidad») hasta situación actual en la que la personalidad única que establece Lisboa no deja de plantear aún dudas («crisis de personalidad»).

\begin{abstract}
The question dealing with the legal personality of the European Union has been very controversial. Until the entry into force of the Treaty of Lisbon, the European treaties did not expresly award legal personality to the European Union but they did recognized it to the Communities. The dualism EC/EU is a consequence issued from the so-called two souls of the integration process (the community path and the intergovernmental path) and has raised several problems ad extra (internacional representation of both EC and EU) and ad intra (the
\end{abstract}


strict separation in pillars has not respond to the case-by-case reality which has challenged this division). The last reform substitutes the last structure for a new on in which it expresly awards legal personality to a brand new European Union, but not all the problems has been solved as a result of this recognition: EURATOM stays alive, it seems that a kind of de facto "pillarization» also remains within the European Union system and the international representation of the new entity is subject to a very limited regulation. In this paper, we will analyze the aforementioned questions, from the co-existence of the dualism $\mathrm{EC} / \mathrm{EU}$ ("dual personality») to the current situation in which the single personality that establishes the Lisbon Treaty still arises questions that has to be solved («personality disorders»).

\section{Palabras clave}

Personalidad jurídica, UE, Tratado de Lisboa, relaciones internacionales.

\section{Keywords}

Legal personality, EU, Lisbon Treaty, international relations. 